\title{
Shortening the duration of treatment for cervical tuberculous lymphadenitis
}

\author{
J.H. van Loenhout-Rooyackers' ${ }^{+}$, R.J.F. Laheij*, C. Richter ${ }^{\#}$, A.L.M. Verbeek*
}

Shortening the duration of treatment for cervical tuberculous lymphadenitis. J.H. van Loenhout-Rooyackers, R.J.F. Laheij, C. Richter, A.L.M. Verbeek. (C)ERS Journals Ltd 2000. ABSTRACT: The aim of the study was to determine the optimal duration of treatment for patients with tuberculous lymphadenitis.

The Medline database was searched for relevant articles published between 19781997. Inclusion criteria were study populations of patients with predominantly cervical tuberculous lymphadenitis in whom the diagnosis had been confirmed bacteriologically and/or histologically, or was made probable by using clinical and laboratory markers. Treatment management had to include at least isoniazid, rifampicin and pyrazinamide and a follow-up of at least 12 months after the end of treatment. Patients with resistance to rifampicin and pyrazinamide and previous treatment for tuberculosis were excluded. The number of patients who relapsed after treatment was calculated.

The study population in eight out of the 35 articles retrieved were suitable for analysis. Some concerned comparative studies. There were eight treatment schedules of 6 months' duration and three schedules of 9 months' duration. Treatment for 6 months resulted in a tuberculous lymphadenitis relapse rate of $13 / 422=3.3 \%(95 \%$ confidence interval: 1.7-5.5), with a mean follow-up of 31 months after completion of treatment. Treatment for 9 months resulted in a relapse rate of $3 / 112=2.7 \%(95 \%$ confidence interval: $0.6-7.8$, with a mean follow-up of 20 months.

Despite the limitations of the literature available, 6 months of therapy is probably sufficient for patients with tuberculous lymphadenitis.

Eur Respir J 2000; 15: 192-195.
${ }^{+}$GGD Regio (Public Health Office) Nijmegen, Nijmegen, the Netherlands. *Dept of Epidemiology, University of Nijmegen, Nijmegen, the Netherlands. " Rijnstate Hospital, Arnhem, the Netherlands

Correspondence: J.H. van Loenhout-Rooyackers

GGD Regio Nijmegen

Groenewoudseweg 275

6524 TV Nijmegen

the Netherlands

Fax: 31243226980

Keywords: Drug therapy

lymph node

relapse

treatment failure

tuberculosis

Received: April 41999

Accepted after revision July 251999
Lymph node tuberculosis, occurring predominantly in the cervical region, is the most common manifestation of extrapulmonary tuberculosis [1].

In the Netherlands, the total number of tuberculous patients is about 1,600 a year, of whom 530 cases have extrapulmonary tuberculosis [2]. The case definition of extrapulmonary tuberculosis at several sites depends on the site with the most severe disease. Cervical tuberculous lymphadenitis $\left(\mathrm{n}=200 \cdot \mathrm{yr}^{-1}\right)$ and pleuritis $\left(\mathrm{n}=200 \cdot \mathrm{yr}^{-1}\right)$ are the most common localizations of extrapulmonary tuberculosis [2]. Lymph node tuberculosis is classified as a less severe form of extrapulmonary tuberculosis. Patients feel less ill and there is neither a significant acute threat to life nor a risk of subsequent severe handicap. Considerations for appropriate treatment are disease severity determined by bacillary load, extent of the disease and anatomical site. In the Netherlands, recently the duration of treatment for pulmonary tuberculosis with sensitive tubercle bacilli ( $M y$ cobacterium tuberculosis) has been shortened from 9 to 6 months on the basis of literature data, using the percentage of bacteriologically proven relapses as the criterion [3]. In contrast, in some countries, like the Netherlands, the duration of treatment for lymph node tuberculosis is still 9 months. The authors reviewed the existing literature to determine whether 6 months of treatment for tuberculous lymphadenitis is justifiable.

\section{Methods and definitions}

The Medline database was searched for relevant articles published from 1978-1997 using the keywords: tuberculosis; lymph node; and drug therapy, with restriction to the English language. In the 1950s pyrazinamide was used in high doses, but it proved to be toxic. Nowadays it is routinely used in each combination of anti-tuberculosis drugs in the initial phase of treatment, because in 1978, it was discovered that lower doses of pyrazinamide were also effective. All of the retrieved publications were screened for the following six inclusion criteria: 1) isoniazid, rifampicin and pyrazinamide had been included in the treatment schedule, possibly with ethambutol and/or streptomycin in adequate doses [4]; 2) treatment had been applied daily or intermittently, supervised or self-administered; 3 ) (combinations of) tablets of proven adequate bioavailability had been used; 4) the diagnosis had been confirmed either by detection of acid-fast bacilli in direct smears from fine needle aspiration (FNA) or from biopsy and/or by positive mycobacterial culture of biopsy and/or by histological evidence of caseating or necrotizing granulomas (clinical diagnosis with response to therapy, without bacteriological or histological evidence, was also included) [5]; 5) cases were not resistant to rifampicin and pyrazinamide; 6) follow-up after the end of treatment had to be at least 12 
months. Studies on patients with active pulmonary parenchymal disease (but not isolated mediastinal lymphadenopathy) or active tuberculosis at sites other than lymph nodes, were excluded. Furthermore, patients with concomitant renal, hepatic or haematological disease and patients who had previously received $>1$ month of treatment for tuberculosis or who had missed $>14$ consecutive or cumulative doses, were excluded from the analysis.

Treatment failures were also excluded from the analysis. Failure was defined as a residual lymph node at the end of treatment, either without any decrease in size or with a size of $>1 \mathrm{~cm}$. Patients with suspicious residual nodes were only excluded if they had been reassessed by FNA, biopsy or had received additional treatment.

Relapse was defined as recurrence of a (residual) lymph node or the appearance of a new node confirmed to be tuberculous after one full course of medication with a period of initial clinical remission. To explore differences in treatment duration, a stratified analysis was carried out. From each study, the authors calculated the rate of relapse after the end of treatment, with a $95 \%$ confidence interval $(95 \%$ CI) [6].

\section{Results}

Eight out of the 35 articles met the criteria. As some concerned comparative studies, there were eight treatment schedules of 6 months' duration and three schedules of 9 months' duration [7-14]. Two articles used the same study population; one reported the preliminary results, the other the final results $[10,11]$. The total number of patients was 644 (table 1). In 229 patients FNA had been performed, while in 291 a biopsy (excisional or incisional) had been taken. The diagnosis had been bacteriologically proven by culture in $349(54 \%)$ and histologically proven in 315 (49\%). In 259 patients M. tuberculosis had been sus- ceptible to isoniazid, rifampicin and pyrazinamide; in 346 patients sensitivity had not been tested or reported; 17 patients were resistant to isoniazid, 11 to streptomycin and 11 to isoniazid and streptomycin. Clinical and laboratory parameters were not reported in detail and could therefore not be analysed. The treatment outcome of patients with bacteriologically proven or suspected tuberculosis was not given separately in the studies.

The dose of anti-tuberculous drugs used varied and was not reported in one study [14]. In adults, the dose of isoniazid used was $300 \mathrm{mg}$ daily or $10-15 \mathrm{mg} \cdot \mathrm{kg}^{-1}$ intermittently. In children, the isoniazid dose was 15-30 $\mathrm{mg} \cdot \mathrm{kg}^{-1}$ twice or thrice weekly $[8,9]$. The same dose of rifampicin and ethambutol was given to adults and children (mg.kg body weight $\left.{ }^{-1}\right)$ : rifampicin: $10-15 \mathrm{mg} \cdot \mathrm{kg}^{-1}$, $450 \mathrm{mg}<50 \mathrm{~kg}$ and $600 \mathrm{mg}>50 \mathrm{~kg}$; ethambutol: 15 $\mathrm{mg} \cdot \mathrm{kg}^{-1}$. Adults received of pyrazinamide $1.5-2 \mathrm{~g}<50$ $\mathrm{kg}$ and $2-2.5 \mathrm{~g}>50 \mathrm{~kg}$ while children received 45-60 $\mathrm{mg} \cdot \mathrm{kg}^{-1}$. Adults received streptomycin $1 \mathrm{~g}$ while children received $40 \mathrm{mg} \cdot \mathrm{kg}^{-1}$, to a maximum of $750 \mathrm{mg}$. Sideeffects were reported in 37 patients, 26 patients were not compliant and 27 were lost to follow-up for other reasons.

During treatment, new nodes or enlargement of existing lymph nodes occurred in $79 / 468=17 \%[7,8,10,11,13]$. Nodes were present after treatment in $143 / 423=34 \%$ of the patients $[7,8,10,11,13]$. The size of the nodes was not reported, or the nodes were not suspected of harbouring disease. If the diameter was $>1 \mathrm{~cm}$ and/or clinically suspicious, tissue was sent for culture before treatment was restarted.

In $5 / 9$ patients with reported failure, the unfavourable outcome was bacteriologically proven $(9 / 553=1.6 \%)$ (table 1) $[8,12]$. In one of these patients, the residual lymph node resolved spontaneously within 3 months and another patient with a residual node of $1 \mathrm{~cm}$ at the end of treatment was lost to follow-up [13].

Table 1. - Treatment for patients with tuberculous lymphadenitis based on published data: 6 and 9 months with isoniazid $(\mathrm{H})$, rifampicin $(\mathrm{R})$ and pyrazinamide $(\mathrm{Z})$

\begin{tabular}{|c|c|c|c|c|c|c|c|c|c|c|}
\hline \multirow[b]{2}{*}{ [Ref.] } & \multirow[t]{2}{*}{ Regimen } & \multirow[t]{2}{*}{ Patients } & \multicolumn{3}{|c|}{ Patients lost } & \multirow[t]{2}{*}{ Failures } & \multicolumn{2}{|c|}{ Cure rate $\% *$} & \multirow{2}{*}{$\begin{array}{l}\text { Follow-up } \\
\text { (months) }\end{array}$} & \multirow{2}{*}{$\begin{array}{l}\text { Relapse rate number } \\
\text { of patients }\end{array}$} \\
\hline & & & $\begin{array}{l}\text { Side- } \\
\text { effects }\end{array}$ & $\begin{array}{l}\text { Non- } \\
\text { compliant }\end{array}$ & Other & & $\begin{array}{l}\text { Intention } \\
\text { to treat }\end{array}$ & $\begin{array}{c}\text { Per } \\
\text { protocol }\end{array}$ & & \\
\hline \multicolumn{11}{|c|}{6 months' therapy } \\
\hline [7] & $6 \mathrm{~S}_{3} \mathrm{H}_{3} \mathrm{R}_{3} \mathrm{Z}_{3}$ & 123 & 3 & 14 & 1 & 0 & 85 & 100 & $36-$ & $4 \star 105(3.8 ; 1.1-9.5)$ \\
\hline$[8] * *$ & $2 \mathrm{~S}_{3} \mathrm{H}_{3} \mathrm{R}_{3} \mathrm{Z}_{3} / 4 \mathrm{~S}_{2} \mathrm{H}_{2}$ & 175 & 2 & 3 & & $2^{\#}$ & 96 & 99 & $36+$ & $3^{\#} / 166(1.9 ; 0.4-5.4)$ \\
\hline$[9]^{* *}$ & $2 \mathrm{H}_{2} \mathrm{R}_{2} \mathrm{Z}_{2} / 4 \mathrm{H}_{2} \mathrm{R}_{2}$ & 15 & & & & & 100 & 100 & $24-$ & $0 / 15$ \\
\hline$[9]^{* *}$ & $2 \mathrm{HRZ} / 4 \mathrm{H}_{2} \mathrm{R}_{2}$ & 12 & & & 1 & & 100 & 100 & $24-$ & $0 / 11$ \\
\hline$[10,11]$ & $2 \mathrm{HRZ} / 4 \mathrm{HR}$ & 66 & 6 & 2 & 6 & 1 & 77 & 98 & $24-$ & $3 / 51(5.9 ; 1.2-16.2)$ \\
\hline$[12]$ & $4 \mathrm{~S}_{3} \mathrm{H}_{3} \mathrm{R}_{3} \mathrm{Z}_{3} / 2 \mathrm{H}_{3} \mathrm{R}_{3}$ & 49 & 4 & 2 & & $2^{\#}$ & 84 & 95 & $21+$ & $2 / 41(4.9 ; 0.6-16.5)$ \\
\hline [13] & $2 \mathrm{HRZ} / 4 \mathrm{HR}$ & 57 & 5 & 1 & 10 & 2 & 68 & 95 & $20-$ & $1 / 29(3.5 ; 0.1-17.8)$ \\
\hline$[14]$ & $2 \mathrm{HRZ}(\mathrm{E}) / 4 \mathrm{HR}^{* * *}$ & $4 * * *$ & $1 * * *$ & & & 0 & $93 * * *$ & $100^{* * *}$ & $12-$ & $0 / 4$ \\
\hline \multicolumn{11}{|c|}{9 months' therapy } \\
\hline$[10,11]$ & $2 \mathrm{HRZ} / 7 \mathrm{HR}$ & 70 & 3 & 1 & 9 & 1 & 79 & 98 & $21-$ & $2 / 56(3.6 ; 0.5-12.3)$ \\
\hline$[12]$ & $4 \mathrm{~S}_{3} \mathrm{H}_{3} \mathrm{R}_{3} \mathrm{Z}_{3} / 5 \mathrm{H}_{3} \mathrm{R}_{3}$ & 64 & 13 & 3 & & $1^{\#}$ & 73 & 98 & $21+$ & $1 / 47(2.1 ; 0.1-11.3)$ \\
\hline$[14]$ & $2 \mathrm{HRZ}(\mathrm{E}) / 7 \mathrm{HR}^{* * *}$ & 9 & & & & 0 & $93 * * *$ & $100 * * *$ & $12-$ & $0 / 9$ \\
\hline
\end{tabular}

Data are presented as absolute numbers with percentage and $95 \%$ confidence interval in parentheses. *: cure rate intention to treat: number of patients cured/starters therapy. Cure rate per protocol: number of patients cured/number of patients, who completed therapy as planned; **: children, age <13 yrs [8], <15 yrs [9]; ***: 4 patients $4 \mathrm{HR}, 9$ patients $7 \mathrm{HR}, 1$ patient $>10 \mathrm{HR}$; : bacteriologically proven; : histologically proven; + : treatment supervised; - : treatment not supervised. S: streptomycin; E: ethambutol. In the "Regimen" column, numbers before a group of letters represent the number of months on that type of drug, numbers after a letter or group of letters represent the number of doses of the drug(s) per week, and if a letter or group of letters is not followed by any numbers then the drug(s) were given daily. 
A total of 534 patients completed treatment and followup as planned (table 1). After a mean follow-up of 29 months, nodes were still present in $41 / 378=11 \%[7,8,10$, 11]. However, the number of patients with a relapse on clinical grounds after successful treatment of 6 months' duration was $13 / 422=3.3 \% 95 \%$ CI $1.7-5.5$, mean follow-up 31 months). After 9 months of therapy, 3/112= $2.7 \%$ (95\% CI $0.6-7.8$, mean follow-up 20 months) relapsed. In three out of these 16 patients, the relapse was bacteriologically confirmed, while in four it was histologically proven $[7,8]$. Five patients relapsed during the first year $[7,8,13]$ three patients relapsed later, and in eight patients there was no further information [7-12].

\section{Discussion}

The authors addressed the question of whether the duration of treatment for tuberculous lymphadenitis can be safely reduced to 6 months. Most recent national and international treatment guidelines also recommend a 6 month therapy $[4,15,16]$. The current meta-analysis supports these recommendations.

The relevant literature was analysed using the relapse rate as the criterion. Follow-up was at least 12 months after the end of treatment. The shortage of literature with welldefined treatment results for tuberculous lymphadenitis made analysis very difficult. Out of necessity, the authors limited the analysis to patients with predominantly cervical tuberculosis. In general, cervical tuberculous lymphadenitis is one of the less severe manifestations of tuberculosis. Active tuberculous disease at other sites cannot always be ruled out completely. It is important for the diagnosis to be bacteriologically confirmed, not only to exclude other diagnoses, but also to obtain material for determination of the organism and susceptibility tests.

In contrast with high-prevalence countries, tuberculosis in low-prevalence countries is not the most frequent cause of lymphadenopathy. Persons infected with human immunodeficiency virus (HIV) have an increased frequency of mycobacterial infections in general, often affecting, the lymph nodes. Care providers should be aware that in these patients $M$. tuberculosis is not always the cause of lymphadenopathy. HIV-positive patients were not included in the present analysis, because the authors could not find any literature with a follow-up of at least 12 months after the end of treatment and no cases of infection were restricted to the lymph nodes [17].

FNA is the diagnostic procedure of choice. If this falls to be conclusive, excisional biopsy is the next step $[5,18]$. The diagnosis of tuberculosis was confirmed bacteriologically and histologically in $54 \%$ and $49 \%$ of the cases, respectively. As a result, treatment outcomes in patients with bacteriologically or histologically proven disease and in patients with suspected tuberculosis on clinical grounds, were merged and could not be analysed separately. Rest nodes did not always mean an unfavourable outcome. The latter was defined as treatment failure or relapse not only proven bacteriologically or histologically, but also on clinical grounds. The decision to perform a second diagnostic procedure or start retreatment depended on clinical judgement. The bacteriologically proven diagnosis depended on the bacillary load and the diagnostic approach. In contrast with smear-positive pulmonary tuberculosis, bacteriological confirmation of a cure is not available. However an immunological response to the antigens released from the dead bacilli may be reflected by the development of new nodes, increases in diameter, or complications such as sinus and abscess formation during treatment or follow-up [11].

The recommendations of the World Health Organisation (WHO) for anti-tuberculous drugs were not strictly adhered to [7-9]. Doses (mg.kg body weight ${ }^{-1}$ ) of essential drugs for the treatment of tuberculosis should be the same in adults and children [4]. Resistance may have been induced by human failure (incompliance) when treatment was not supervised. Nevertheless the clinical outcome was satisfactory in most cases. Such favourable outcomes may be explained by the small number of bacilli in such patients and the low resistance rate. In the group of patients with tuberculous lymphadenitis treated for 6 months 3.3\% relapsed, while those treated for 9 months had a relapse rate of $2.7 \%$. Treatment for pulmonary tuberculosis for 6 months with a regimen including isoniazid, rifampicin and pyrazinamide resulted in a relapse rate of $116 / 4,833=2.4 \%$ (95\% CI: 2.0-2.8, follow-up 12-94 months) [3]. Differences were not statistically significant.

In studies on pulmonary tuberculosis, only patients with bacteriologically proven, fully sensitive tuberculosis are analysed. Treatment failures and relapses can be bacteriologically proven [3]. The suggestion that a low bacillary load may justify an even shorter length of treatment, e.g. 4 months, needs to be investigated [19]. However, sterilization of lesions depends on the persistence of (semi) dormant bacilli, but on theoretical grounds this may be unrelated to the bacterial load. In pulmonary tuberculosis, relapses mostly occur within 12 months after the end of treatment. Therefore, for prospective studies, a follow-up of 24-30 months is generally enough [3]. The risk of relapse in lymph node tuberculosis is unknown, but the small number of relapses during follow-up in the retrieved articles confirms the advice given by the Joint Tuberculosis Committee of the British Thoracic Society: after successful treatment, follow-up is not required but patients should be re-referred if symptoms recur [15].

In conclusion, it seems justified to administer medication for 6 months, including isoniazid, rifampicin and pyrazinamide, for tuberculous lymphadenitis (as the individual authors of the retrieved articles suggested). A large proportion of patients had rest nodes. Relapses occurred within 12 months after the end of treatment, but later was also possible. The small number of patients described in the literature makes consensus about diagnostic procedures and treatment schedules important, because investigators have to depend on pooled data and office-based analyses. Therefore data must be gathered in the same way to enable sound clinical judgements and to formulate therapeutic guidelines.

\footnotetext{
Acknowledgements. The authors thank R. van Altena, J. Veen and J.W.M. van der Meer for their comments and useful advice.
}

\section{References}

1. Mehta JB, Dutt AC, Harvill L, Mathews KM. Epidemiology of extrapulmonary tuberculosis. A comparative analysis with pre-aids era. Chest 1991; 99: 1134-1138. 
2. Index Tuberculosis 1996. KNCV, The Hague, the Netherlands, Oct 1997.

3. van Loenhout-Rooyackers JH, Veen J, Verbeek ALM. Verkorting van de therapieduur bij patienten met longtuberculose van 9 naar 6 maanden verdedigbaar op grond van gepubliceerde gegevens. Ned Tijdschr Geneesk 1996; 44: 2181-2187.

4. Treatment of tuberculosis: guidelines for national programmes. WHO. 2nd Ed. 1997.

5. Perenboom RM, Richter C, Swai ABM, et al. Diagnosis of tuberculous lymphadenitis in an area of HIV infection and limited diagnostic facilities. Trop Geogr Med 1994; 46: 228-292.

6. Lentner C. Wissenschaftliche Tabellen. Basel, Switzerland, Ciba-Geigy, 1968

7. Cheung WL, Siu KF, Ng A. Six-month combination chemotherapy for cervical tuberculous lymphadenitis. $J R$ Coll Surg Edinb 1990; 35: 293-295.

8. Jawahar MS, Sivasubramanian S, Vijayan VK, et al. Short course chemotherapy for tuberculous lymphadenitis in children. BMJ 1990; 301: 359-361.

9. Kumar L, Dhand R, Singhi PD, Rao KLN, Katarya S. A randomized trial of fully intermittent versus daily followed by intermittent short course chemotherapy for childhood tuberculosis. Pediatr Infect Dis J 1990; 9: 802806.

10. British Thoracic Society. Six-months versus nine-months chemotherapy for tuberculosis of lymph nodes: preliminary results. Respir Med 1992; 86: 15-19.
11. Campbell IA, Ormerod LP, Friend JAR, Jenkins PA, Prescott RJ. Six months versus nine months chemotherapy for tuberculosis of lymph nodes: final results. Respir Med 1993; 87: 621-623.

12. Yuen APW, Wong SHW, Tam CM, Chan SL, Wei WI, Lau SK. Prospective randomized study of thrice weekly six-month and nine-month chemotherapy for cervical tuberculous lymphadenopathy. Otolaryngol Head Neck Surg 1997; 116: 189-192.

13. McCarthy OR, Rudd RM. Six months' chemotherapy for lymph node tuberculosis. Respir Med 1989; 83: 425427.

14. Pang SC. Mycobacterial lymphadenitis in Western Australia. Tuber Lung Dis 1992; 73: 362-367.

15. Joint Tuberculosis Committee of the British Thoracic Society. Chemotherapy and management of tuberculosis in the United Kingdom: recommendations 1998. Thorax 1998; 53: 536-548.

16. ATS. Treatment of tuberculosis and tuberculosis infection in adults and children. Am J Respir Crit Care Med 1994; 149: 1359-1374.

17. Perenboom RM, Richter C, Swai AB, et al. Clinical features of HIV seropositive and HIV seronegative patients with tuberculous lymphadenitis in Dar es Salaam. Tuber Lung Dis 1995; 76: 401-406.

18. Snow GB. Consensus diagnostiek van een verdachte halslymfklier. Ned Tijdschr Geneesk 1988; 132: 114-119.

19. Dutt AK, Stead WW. Treatment of extrapulmonary tuberculosis. Semin Respir Infect 1989; 4: 225-231. 